\title{
The Development and Narrative Strategy of Internet Adapted Drama
}

\author{
Lili Huang \\ College of Humanities and Communication \\ Heihe University \\ Heihe, China 164300
}

\begin{abstract}
In recent years, the diversification of economy and culture, the essential features of online fiction, the demand for the development of the TV drama market and the wide spread of the Internet have prompted the organic combination of internet fiction and television dramas. On the basis of clarifying the relationship between internet fiction and television dramas, it is of some practical significance to conduct an in-depth analysis from the narrative level of the internet fiction and television dramas.
\end{abstract}

Keywords-internet fiction; TV drama; narrative strategy; adaptation

\section{INTRODUCTION}

In this information-sharing and data-gathering era of Internet information, the combination of internet fiction and TV series is not an accident. The Internet adaptation is an inevitable outcome with the development of the era. Internet fiction broadens the development of TV drama market and opens up a new situation for the production of TV series.

\section{THE RISE OF NETWORK ADAPTATION DRAMA}

From the first adaptation of the drama series "The First Intimate Contact", which adapted by mainland China's first online novel of the same name, to the screen hit series "You Are My Sunshine", "Nirvana in Fire", "The Pretender", "Legend of Concubine Zhen Huan", "Legend of Miyue", "The Journey of Flower", "Ten great III of peach blossom", etc., these works are adapted by the network novels. The online fictions are adapted into dramas, which has also become a common phenomenon in today's television drama market. At present, the adaptation of online fiction is in the ascendant phase. Many online adaptation plays have been popular with television viewers. Many adapted internet dramas are being prepared for filming. The makers of the television series have purchased the copyright of related online fictions. They join the mighty team of Network adaptation dramas.

The reason why the network adaptation plays can seize the market with a strong attitude is inseparable from the vigorous development of the internet novel. In 1998, the novel "The First Intimate Contact" was highly popular in the online forum. With astonishing stance, it attached the public attention. The unique theme of the novel also aroused the attention of TV series creators. And then these creators opened the vigorous development history of network adaptation.

\section{THE DEVELOPMENT OF NETWORK ADAPTATION DRAMA}

In 2004, the "First Intimate Contact" adapted by the online fiction with same title firstly were on the screen. It was the first time that internet fiction and drama had been combined. During the next five years, the growth of network adaptation plays shows gradual increase. Many works have entered the audience's field of vision. Many works have been widely praised. Works such as "Dwelling Narrowness" and "Double Sided Adhesive Tape" are all created in this period. In 2010, network adaptation drama began to enter the stage of accelerated development. The masterpiece "Schemes of a Beauty" got high ratings. And then, the network adaptation drama had the explosive growth. "Legend of Concubine Zhen Huan", "Nirvana in Fire" and a series of high-quality works continuously emerged.

In recent years, the network adaptation play occupies half of the TV market with strong development. The spy and suspense drama "The Pretender", ancient costume and imperial-harem competing play "Legend of Miyue", urban emotional drama "Ode to Joy", ancient costume and right competing play "Nirvana in Fire", ancient fantasy drama "Ten great III of peach blossom" and other novel adaptations continue to attract a large number of audiences nationwide and get high ratings as well as high reputation. Nowadays, the rising star of this network adaptation fiction plays a decisive role in the Chinese TV market.

\section{THE BASIC CHARACTERISTICS OF NETWORK ADAPTATION DRAMA}

Network adaptation plays often could be divided into royal court play, urban love play, suspense play, time-travel TV series, fantasy play and other types of online TV series. In general, network adaptation plays have diverse features.

\section{A. The Categorization of Network Adaptation Drama}

The categorization of Network adaptation drama could be divided into three types. The works are mainly in romance drama, royal court play and urban life drama. For the 
development of network adaptation plays, categorization is an advantage but also a disadvantage. With the emergence of more works of the same type, people would pay more attention to these works over a period of time. However, with the emergence of multiple works of the same type, people would only pay attention to these plays in a short time. From a long-term perspective, to a certain extent, the typification would limit the performance of the drama, and keep from the development of TV drama market.

\section{B. The Linearization of Narrative Method}

The linearization of narrative method, extremely rhythmic narrative plot and clear time frame are the narrative characteristics of the network adaptation drama. The method focuses on reflecting the figures and events in a specific historical context. With the historical and social background, the play could show the personality and commonalities of human nature, the social warmth, the joys and sorrows of the family in the context of specific historical time. The TV dramas such as "Dwelling Narrowness", "Schemes of a Beauty", "Legend of Miyue" have used this kind of narrative methods.

\section{To Focus on the Development of the Character}

The content of network adaptation plays focuses on the development of character, the twists and turns of life and destiny, the change of families in national society and the uniqueness of the relationship between morality and ethics. Generally speaking, the drama would adopt the narrative method of alternately using the first person and the third person. It would make the development of the story more smooth and natural. And the narrative structure of the story is also more regulated. However, in the narrative of network adaptation plays, the core clue of network novel still plays the important function of narration throughout the TV series.

\section{Conflicts Rely on Emotional Entanglements}

Network adaptation plays take the emotional conflicts as the basis of the conflict. And most of the works are concentrated in the feelings of men and women, gender relations. The ancient fantasy drama and urban romance drama tell the story of romantic life. In a certain historical background and social environment, these kinds of works integrate affective clues such as affection, love and friendship. With the setting of dramatic conflicts, these works reflect the change of sentiment among people. During the adaptation of online novels into TV series, it makes good use of this point. In the process of reorganization, the creators would deal the internet novels with the rational artistic processing. And the key storylines are deduced in detail, which makes the drama productions more intense and complex. In the end, it would achieve the real ideal audiovisual effects.

\section{THE NARRATIVE RELATIONSHIP BETWEEN ONLINE NOVELS AND TV SERIES}

At present, there are three script sources for the drama. The first is to make the creation based on the theme of the
TV series. The second is to select traditional literary works. The third is to adapt online novels. [1]Under the background of the rapid development of popular culture, internet novels emerge, flourish and gradually become the outstanding literary forms distinct from the traditional literature. The online novels have wide audience. And online novels have been paid close attention to by screenwriters and gradually take the lead in the production of TV series. In recent years, Internet fiction has become the hot selection target of TV scripts, which is very popular and has great potential.

The basic rules of artistic creation are similar. The purpose is to shape the vivid character images, and express profound and rich thoughts and emotions, and create unique artistic styles. In terms of narration, the new literary form of internet fiction belongs to the narrative art just as the TV dramas . The former is to make narrative on the basis of the characters. And the latter takes the image as the carrier is to make narrative. Narrative is the most important value of the adaptation.

Online novels provide rich themes, a stable audience base and relatively free adaptation space for the drama. On the basis of narrative, we could adapt the network novel into the TV series. And we could make the integration of two sides. The internet adaptation plays would transfer the text and the abstract into image. And this change makes TV drama more vivid than online novel. In this process, narrative is the bridge and the commonality between the internet novels and the TV dramas.

On the one hand, online novels bring rich scripting resources, solid audience base and limitless development space to the drama. And it has also accelerated the development of the drama. On the other hand, the adaptation of online novels into TV dramas has promoted the popularity of online novels and online writers. Also, it has broadened the channels for the development of online novels. And it has promoted the continuous development of online novels.

\section{ANALYSIS ON THE NARRATIVE STRATEGY OF NETWORK ADAPTATION DRAMA}

Both online fiction and TV series are narrative art, and online fiction is transformed into television series. In fact, it is essentially a shift from narrative art to another narrative art. In the process of transformation, based on narrative commonness, the two are integrated and blended with each other to maximize the imaginative reproduction of the characters and scenes in the network fiction. This unique artistic exposition also needs to meet the aesthetic demands of the overwhelming majority of the public. Also, it should be in line with the current doctrine of values. As the drama of narrative art, the selection and application of narrative strategies directly determine the survival of the entire drama.

\section{A. The Changes of Narrative Structure}

In the "Narrative Dictionary', "structure" is interpreted as "a network of relationships among the various components and relationships between each component and the whole entity". [2] The narrative structure is the frame structure of 
the story. On this basis, it would show the order and style of the narrative.

In the hit drama "Ten great III of peach blossom", the story frame and the clue are mutually consistent with the original work. And the characters' relations, the images, the characters and the characters' growth experience are basically the same with the novel. Even, the lines directly use the character dialogue in original novels. In the process of reorganization, the TV dramas basically restore the story of the novel. At the same time, the narrative mode is changed from the narration interspersed with flashbacks to the chronological order. After carding ideas, the TV dramas make the order of the original flashback prequel, wedge and the back of the content in accordance with the time sequence. And then, it cleverly combed the narrative structure. This adaptation makes the narrative context of drama more clear, helps the audience better cut into the story and understand the story more thorough. At the same time, it is also a more appropriate summary of the theme of drama.

\section{B. The Conversion of Narrative Language}

The narrative language conversion from online novels into TV series is actually a second creation on the basis of internet fiction. The process of adaptation is the audio-visual expression of literary language. The aim is to make the character dialogue more popular. In the term of emotion, it would expressive distinctive personality.

In recent years, internet language is common in online novels. Therefore, in the adaptation process, adapters must adapt the language of the novel to meet the demands of colloquialization and living through the reconstruction of the language in the novel. However, some languages that violate the ethics and values in the network novels need to be reasonably processed. Some of the texts are weakened or even deleted, which can not only meet the entertaining qualities of the drama, but also maximize the reproduction of the visualization of the language in the online novels. It is also a major strategy for the adaptation of narrative language in the internet adaptation drama.

\section{The Adjustment of Character Image}

In the terms of setting the characters, the adaptation drama is generally consistent with the original works. And it is necessary to maintain the essence of characters in network fiction. They also have to reflect the distinctive characteristics of the screen figures. It is the key issues in the process of adapting the network novels. Belinski said that man was the protagonist of the drama. The most powerful means to depict man is to characterize the character and the mind. Therefore, the main characters in the network adaptation play must have distinct ethical characteristics. And the goodness, evil, beauty and ugliness, true and false flirtations should be condensed in different characters. Through this strong contrast, it would form the conflicts in dramas, which would successfully arouse the audience's emotional input.

In "You Are My Sunshine", the emotional development clue between hero and heroine is basically the same as that in the original network novel. However, they have adapted the characters of male No. 2 and female No. 2. And this adaptation makes the emotional competition more intense in the drama. In the original network novel, He Yimei gave up the love of He Yichen shortly after Zhao Meisheng returned home. However, the teleplay stretched He Yimei's emotional entanglement and arranged more episodes. In terms of emotional expression, it would have more levels.

\section{The Settings of Conflicts in Drama}

Hegel regarded "the conflicts of various purposes and personalities" as the "central issue" of drama. [3] Drama conflict is a special art form used in drama to express the contradiction among people and the inner contradiction of people. Conflict is the basis and motive force for the development of TV series. There are three kinds of conflicts: conflict among people, conflict within people and conflict between people and environment. The rhythm of long online novels is slow. The conflict is not obvious enough. In the adaptation process, the setting of conflict in drama is one of the great difficulties.

"Legend of Concubine Zhen Huan" is a typical TV series with strong drama and narrative style. The heroine had undergone countless conflicts during the growth from daughter of a humble family to the power center of the Palace. And the audiences are always in a state of tension and anticipation. For example, in the drama of Drop Renqin, the narrative clues included the suspicion of the emperor, the secret imprisonment of the Queen, the inner changes of Zhen Huan and the transformation of Qi concubine from happiness to lose. The intense conflict made the audience feel nervous. As the problem was solved, the audience was relieved.

\section{CONCLUSION}

With more than 10 years' development, the adaptation of online novels into TV series has created a good situation of mutual benefit and win-win situation. From the perspective of adapters, they should know how to choose the angle and direction of adaptation and how to creatively make up the difference. The works have certain historical thickness, ideological depth and artistic height while preserving its basic characteristics, which is a great challenge. We should also deepen the related researches. And it would provide an inexhaustible motive force for the development of this art form.

\section{REFERENCES}

[1] Shan Linlin. Analysis on the market of Chinese TV dramas [D] Shanghai, Tongji University, 2008.

[2] Gerald Prince. Narrative Dictionary [M]. Shanghai Translation Publishing House, 2011.

[3] Hegel. Aesthetics [M]. The Commercial Press, 1982: 278. 